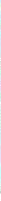

Artículo de reflexión E16A09. * Recibido: 13.03.2020. * Aprobado versión final: 25.06.2020. JEL: J44, M40, M41, Q56. * Pp. 79-89 * doi: 10.33571/teuken.v11n17a4

\title{
Redefiniendo al Auditor desde la Bioética.
}

\section{Redefining the auditor from bioethics.}

\author{
Percy Iván Aguilar Argueta \\ GUATEMALA
}

\begin{abstract}
Resumen: El lavado de dinero, el narcotráfico, el tráfico de personas y órganos, cada día son más comunes y ganan adeptos para la realización de negocios, incluso para su posible legalización. En ese entorno el auditor debe desarrollar su ejercicio profesional. Los códigos de ética han sido incapaces de dotar de elementos a los auditores para tomar decisiones prudentes y así alejarse de instituciones involucradas en actos anómalos; por el contrario, a través de los informes respaldan a la administración convirtiéndose en cómplice. Se ve a la ética como algo relacionado al cumplimiento de normas, sin que se le relacione con la moral, la vida y el efecto del trabajo del contador y el auditor. En ese contexto, la bioética relaciona el efecto que el acto de un ejercicio profesional tiene con la vida de las personas.
\end{abstract}

Palabras clave: auditor; auditoría; lavado, corrupción; ética; bioética.

Abstract: Money laundering, drug trafficking, human and organs trafficking, are becoming more common every day and are gaining followers for the conduct of business, including its possible legalization. In this environment, the auditor must develop professional practice. Ethics codes have been unable to provide auditors with elements that allow them to make prudent decisions and thus move away from institutions involved in anomalous acts. On the contrary, through the reports they support the administration by becoming an accomplice. Ethics is seen as something related to compliance with standards, without being related to morality, life and the effect of the work of the accountant and auditor. In this context, Bioethics relates the effect that the act of a professional exercise has with people's lives.

Keywords: auditor; audit; laundering, corruption; ethics; bioethics.

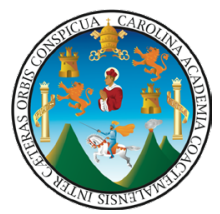

Percy Iván Aguilar es Contador Público y Auditor, Antropólogo y Doctor en Derecho Tributario y Mercantil por la Universidad San Carlos de Guatemala. Actualmente es Profesor Investigador y Director del Departamento de Estudios de Postgrado de la Universidad de San Carlos de Guatemala - Centro Universitario de Occidente.

Contacto: percy.aguilar@cunoc.edu.gt 
Resumo: Lavagem de dinheiro, tráfico de drogas, tráfico de pessoas, órgãos, estão se tornando mais comuns a cada dia e ganham adeptos para a realização de negócios, incluindo sua possível legalização. Nesse ambiente, o auditor deve desenvolver a prática profissional. Os codigos de ética não tem conseguido fornecer aos auditores elementos que lhes permitam tomar decisões prudentes e, assim, afastar-se das instituições envolvidas em atos anômalos. Pelo contrário, através dos relatórios eles apoian a administração tornando-se cúmplice. A ética é vista como algo relacionado ao cumprimento de normas, sem estar relacionada à moralidade, à vida e ao efeito do trabalho do contador e auditor. Nesse contexto, a bioética relaciona o efeito que o ato de um exercício profissional tem na vida das pessoas.

Palavras-chave: auditor; auditoria; corrupção; ética; bioética.

\section{Ética y Bioética}

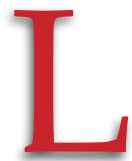

a profesión contable se basa en un elemento que es fundamental para su desarrollo: "la confianza pública", que en algunos países trasciende a la "fe pública". Quien utiliza los informes de auditoría para la toma de decisiones está convencido de que los mismos revelan datos que reflejan una realidad financiera de la empresa o institución, contienen el mínimo de errores y un bajo nivel de riesgo de fraudes o irregularidades. De igual forma cuando el profesional trabaja para el Estado, el examen a la ejecución presupuestal debe evaluar y procurar el eficiente uso de los recursos públicos. Más allá de un trabajo responsable, el ejercicio de la profesión pasa por un compromiso ético, que cuando se involucra en la vida trasciende a otro de carácter bioético.

Ética puede definirse básicamente como un sistema de principios morales y su aplicación a problemas particulares de conducta (Kohler, 1982: 243). A la definición anterior es importante agregar que tal sistema responde al tipo de sociedad que lo adopta. Ética Profesional se define como el conjunto de reglas impuestas por el más alto organismo que regula una profesión, con el objetivo de asegurar un buen desempeño profesional. A este respecto, Kohler define ética profesional como las reglas de conducta de una profesión, impuestas por un cuerpo profesional que gobierna la actuación de sus miembros. (1982: 243). Algo fundamental en la Ética Profesional contable es lo referente al interés público que el Contador debe observar en el ejercicio profesional, significa esto que la profesión responde a un objetivo desde la perspectiva social y no individual; el Código de Ética de IFAC establece:

"Una característica que identifica a la profesión contable es que asume la responsabilidad de actuar en interés público. En consecuencia, la responsabilidad de un profesional de la contabilidad no consiste exclusivamente en satisfacer las 
necesidades de un determinado cliente o de la entidad para la que trabaja. En su actuación en interés público, el profesional de la contabilidad acatará y cumplirá el Código. Si las disposiciones legales y reglamentarias prohíben al profesional de la contabilidad el cumplimiento de alguna parte del Código, cumplirá todas las demás partes del mismo."

Los principios fundamentales de ética profesional establecidos por el Código de Ética de IFAC, son:

"a). Integridad - ser franco y honesto en todas las relaciones profesionales y empresariales.

b). Objetividad - no permitir que prejuicios, conflictos de intereses o influencia indebida de terceros prevalezcan sobre los juicios profesionales o empresariales.

c). Competencia y diligencia profesionales - mantener el conocimiento y la aptitud profesionales al nivel de calidad necesario para asegurar que el cliente o la entidad para la que trabaja reciban servicios profesionales competentes basados en los últimos avances de la investigación, la práctica, la legislación y las técnicas, y actuar con diligencia y de conformidad con las normas técnicas y profesionales aplicables.

d). Confidencialidad - respetar la confidencialidad de la información obtenida como resultado de relaciones profesionales y empresariales y, en consecuencia, no revelar dicha información a terceros sin autorización adecuada y específica, salvo que exista un derecho o deber legal o profesional de revelarla; ni hacer uso de la información en provecho propio o de terceros.

e). Comportamiento profesional - cumplir las disposiciones legales y reglamentarias aplicables y evitar cualquier actuación que pueda desacreditar a la profesión."

En diversos debates profesionales se discute sobre si los principios éticos se refieren con exclusividad al ejercicio profesional. Para algunos expertos el código regula la actuación profesional; en los cuatro primeros principios citados se establece con bastante certeza "la responsabilidad profesional"; por ejemplo, el principio de integridad hace énfasis en que el Contador debe ser franco y honesto en todas las relaciones profesionales y empresariales, aunque no hace referencia a la vida personal. No hacer referencia al comportamiento en la vida privada en los primeros cuatro principios, no significa que no se tengan que observar en ese plano. No es posible imaginar que la profesión de Contador sea como una camisa, que se pone en el día y se la quita en la noche; esto es imposible, se es Contador las veinticuatro horas del día, claro está.

La mesura, la rectitud, el respeto a las reglas de la moral, es un componente propio de la profesión del Contador, que está implícito en su 
actuar en todo momento. El quinto principio establecido por el Código: "Comportamiento Profesional" debe interpretarse en un sentido amplio; la frase: "...evitar cualquier actuación que pueda desacreditar a la profesión" reafirma lo escrito. ¿Qué actuaciones pueden desacreditar a la profesión? Son muchas, las comunes en el trabajo: estar vinculado a un fraude, estafa o acto de corrupción; lavado de dinero, delincuencia organizada, conexiones con funcionarios públicos acusados de corrupción, entre otros. Todos estos hechos dañan a la profesión del Contador, especialmente en países donde el sustento es la confianza que la sociedad tiene en el profesional de la Contabilidad y Auditoría. En este contexto los auditores vinculados a acciones fraudulentas desacreditan la profesión en general y los daños suelen ser irreversibles.

Sin la observancia mínima de los cinco principios éticos regulados y citados en el código, (que para otros países, como el caso de Colombia adiciona cinco más), la profesión contable estaría destinada a desaparecer, por lo menos en los términos en que la conocemos hasta el día de hoy. La ética se complementa con la moral, ambas corresponden en su cumplimiento a una situación de satisfacción para el profesional, no solo de hacer un trabajo competente desde la técnica, sino desde el respeto a las leyes morales y los principios éticos, como lo plantea Plata (2013) recordando las consideraciones filosóficas de Hume y Wittgenstein.

Al respecto, Ospina (2018) recreó de manera certera cómo la pérdida de valores éticos da como resultado el involucramiento en grandes escándalos de corrupción, mismos que son invisibilizados por la protección que algunas grandes empresas encuentran en las instituciones del Estado nacional.

Las empresas van en búsqueda del rendimiento financiero y usan los servicios del Contador Público para alcanzarlo. Es evidente cómo las transnacionales evaden el control fiscal, usan compañías offshore o fuera de plaza, castigando los valores mínimos de lo humano. "Los empresarios están más interesados en las ventajas que ofrece la elución o evasión de impuestos, sobre quien puede darle soluciones para que su recurso humano alcance un mejor desempeño por encima de su bienestary dignidad humana" (Ospina, 2018, p. 32). Es el Estado en su conjunto el que desvaloriza la ética, incluidas las organizaciones civiles, como Colegios de Profesionales, Cámaras de Empresarios, Industriales y Agroindustria.

\section{De la Ética a la Bioética}

Conviene recordar que "la bioética o ética de la vida, implica una visión integradora del conocimiento, cuyo propósito trasciende la discusión por el campo disciplinar y sitúa al sujeto en su responsabilidad frente a sus actuaciones para con la sostenibilidad y permanencia de toda forma de 
vida en el planeta". (Londoño, Sánchez \& Serna, 2020). Esta afirmación nos traslada a un contexto de responsabilidad planetaria, dejando de lado lo egocéntrico y antropocéntrico del profesional contable; postula una obligación de garantizar la vida, el respeto a la naturaleza y la garantía de un mundo mejor desde su ejercicio profesional.

Etimológicamente la palabra Bioética proviene de bios que significa vida y ethos que significa moral. Trata del comportamiento humano en relación con la vida. Aunque para Echenique Portillo, (2008) profesor de la Universidad Nacional Autónoma de México, sus fuentes principales son la ética y la medicina, la Bioética se nutre de otras disciplinas como el derecho, la antropología, la psicología, la sociología, etc. sin embargo en los últimos años los investigadores de las ciencias sociales han aportado estudios que demuestran que todas las disciplinas profesionales se relacionan con la vida y la moral.

La Bioética es parte de la Ética, pues se centra en resolver los problemas prácticos de las ciencias de la vida, como medicina, neurociencias, ecología, y sus problemas: reproducción, aborto, eutanasia, manejo de información genética, la clonación, etc., es un campo multidisciplinario, amplio y complejo. En la ciencia del derecho se ha reconocido el "Bioderecho" y esto hace reflexionar sobre la conexión que existe entre las leyes y la contabilidad, pudiendo entonces iniciar a construir la "Biocontabilidad y Bioauditoría", desde una óptica de respeto a todas las formas de vida.

El daño que ha sufrido la madre tierra y sus efectos en las ciudades, incluso las de primer orden o desarrolladas, así como el avance en procesos tecnológicos de procesamiento de información, han dado lugar a nuevas interpretaciones de la realidad desde la Contabilidad, de allí surge la Biocontabilidad, misma que se encarga del registro y valoración de la riqueza ambiental que controlan las organizaciones (Mejía-Soto, 2013). En consecuencia, los estados contables ambientales que generan los procesos de la Biocontabilidad deben ser auditados, lo que supondría la necesidad de una Bioaditoría.

En 1978 se publicó la primera edición de la Enciclopedia de Bioética, editada por el profesor Warren T. Reich y otros profesores del Instituto Kennedy de Bioética, en donde se define ésta como: "el estudio sistemático de la conducta humana en el área de las ciencias de la vida y del cuidado sanitario, en cuanto que tal conducta se examina a la luz de los valores y de los principios morales" (Echenique Portillo, 2008: 14). ¿Cuáles ciencias de la vida? La relación al inicio fue con la medicina, luego pasó a la biología, física, química, sin embargo, toda ciencia es de la vida. El derecho, por ejemplo, estudia el comportamiento humano, lo regula, sanciona o 
penaliza, afecta la vida de las personas. La economía definitivamente está ligada a la vida de los ciudadanos, el comportamiento humano, los valores y la moral, igualmente la política, la sociología, y sin temor a equivocarme, tiene relación con la auditoría.

En 1979 Tom Beauchamp y James Childress realizaron una publicación titulada "Principios de Ética biomédica", donde desarrollan y profundizan el estudio de tres principios: autonomía, beneficencia y justicia, agregando uno más, el de no maleficencia. La auditoría se fundamenta en la ética, e interpreta a ésta como la honorabilidad de quien la ejecuta, con normas claras fijadas por diferentes organismos reguladores de la profesión, entre los que destaca el Código de Ética de IFAC, sin embargo, ejemplos de fraudes como Worldcom, Enron, Parmalat, y la vinculación en casos de corrupción de organizaciones como Odebrecht, demuestran que los organismos reguladores no han sido capaces de respaldar la profesión con suficientes elementos de ética para su buen ejercicio.

La auditoría tiene una estrecha vinculación con el comportamiento humano, la moral, los valores y principios, y sus resultados afectan la vida de las personas (Sandes y Charamelo, 2017). Para sustentar lo anterior me referiré a dos casos concretos de fraude a un gran grupo de ciudadanos, cuentahabientes de dos bancos guatemaltecos, Banco del Café y Banco del Comercio. Estas instituciones financieras utilizaron los recursos de los ahorradores, sin incluirlos en los Estados Financieros que supervisa la entidad reguladora, los enviaron a Offshore, en paraísos fiscales, y luego desaparecieron sin dejar rastro. Los bancos se declararon en quiebra. El fondo de garantías financieras que existe en Guatemala cubrió las pérdidas de los ahorradores en su totalidad, pero sólo de los que se registraron en los estados financieros. Todos los que se registraron en las offshore no fue posible cubrirlos. En este caso miles de personas perdieron ahorros de toda su vida, llegando a tal nivel de desesperación que, en dos casos, optaron por el suicidio. Si el auditor interno y el externo hubieran sobrepasado la frontera del documento durante los exámenes a los estados financieros, seguramente hubiese descubierto los malos manejos, dejando plasmados los hallazgos en el informe; de haberlo hecho no hubieran muerto seres humanos, quienes se suicidaron luego de saber que habían perdido los ahorros de su vida.

Muchos fraudes no descubiertos por los auditores han tenido consecuencias fatales en la vida de las personas; el profesional de la auditoría debe valorar el efecto que tiene el trabajo que desarrolla en el entorno social en el que se desenvuelve. El mismo impago de impuestos resulta tener consecuencias en la salud y educación de la sociedad. El daño causado por actividades en las que se asocian la empresa privada 
y los gobiernos para obtener beneficios individuales daña a la sociedad y destruye la confianza pública en las instituciones. La visión de los auditores, tanto los que trabajan en el gobierno como los que lo hacen en la empresa privada, debe ser de fidelidad a la sociedad, para reportar estos eventos en los informes correspondientes.

La Bioética le presenta a la auditoría una oportunidad para comprender que los resultados del examen que se publica sobre una sociedad tienen efectos en seres humanos, en las oportunidades de niños y adultos para aspirar a un mejor nivel de vida, en esencia una vida plena, para eliminar o por lo menos disminuir la pobreza y la desigualdad entre los integrantes de una comunidad. Contribuir al buen vivir o vivir en armonía es una obligación de la profesión contable.

El formato estándar del informe o dictamen, emitido por el auditor como producto final del examen realizado, establece claramente que él asume la responsabilidad de haber observado a cabalidad y sin reserva alguna los enunciados de la ética, (NIA 700, 2016). ¿Pero tiene el informe una vinculación con la vida? Por supuesto que sí; el ejemplo de que el informe tiene implicaciones en la vida de las personas se evidencia cuando se sabe de inversionistas y pequeños ahorradores que se han suicidado debido a que perdieron sus inversiones, que según ellos se encontraban seguras en las empresas auditadas. Esa relación comienza desde que el inversionista deposita la confianza en que el profesional de la auditoría aplica elementos de una técnica depurada y reconocida a nivel mundial para el desarrollo del trabajo realizado.

Pero no solo en empresas privadas existen daños a la población, la corrupción es un flagelo que afecta a la sociedad en general. La elusión del pago de tributos también afecta a las sociedades. El mal uso de recursos públicos causa muerte, hambre, pobreza, desigualdad, entre otros males, y los daños son incalculables. En Guatemala y Latinoamérica durante la segunda década del presente siglo han salido a la luz una serie interminable de actos de corrupción gubernamental con el evidente involucramiento de los altos jefes de Estado y no pocas compañías privadas. Guatemala es el mejor ejemplo con la caída del presidente y vicepresidente en funciones, así como la caída de un buen número de Ministros de Estado en 2015 y nuevamente en 2020 y años siguientes. No lejos de esta situación se han visto gobiernos de El Salvador, Honduras, Perú, Argentina y otros que pasan por la misma suerte.

Un emblemático caso de corrupción se descubrió durante el año 2016, cuando Odebrecht, la multinacional brasilera de la construcción de infraestructuras valorada en miles de millones de dólares, pagó cuantiosas 
comisiones ilegales a funcionarios de varios gobiernos de Latinoamérica con el objetivo de obtener contratos de construcción a través de bancos, empresas privadas, operadores políticos, gobernantes, ministros de Estado, etc. En este contexto los países tienen unidades de contraloría, pero éstas no fueron capaces de desarrollar las funciones de manera correcta. Los resultados de las revisiones anuales no arrojaron resultados que evidenciaran anomalías en las que se involucrara a la empresa constructora con proyectos en los países; el escándalo se descubrió por agentes del Ministerio Público, después de que la prensa hiciera la publicación de documentos que involucraban a muchos funcionarios. La revisión de los auditores gubernamentales en la mayoría de casos se centra en documentos, los que revisan y comprueban el cumplimiento de normas legales, plazos, entrega de proyectos y el pago pactado, como si esto no tuviera la más mínima relación con la cotidianidad de la población, que al final la afectada. Lo anterior representa un ejercicio profesional miope, egocéntrico, individualista, quizás sin compromiso con su entorno. Esta forma de actuar del auditor, y la forma de pensar que lo sustenta, debe modificarse.

En el caso internacional de la constructora brasileña Odebrecht puede identificarse a los auditores y vincularlos con diversos actores. En esta empresa constructora, un profesional de la contaduría emitió diversos dictámenes necesarios para la negociación de acciones en las bolsas de valores. Este profesional en lo interno o en lo externo aplicó normativa financiera internacional y lo plasmó en los informes, por tanto, asumió la responsabilidad de actuar en función del interés público, lo que significa que revisó su actuación, pero sobre todo, debió estar consciente de que su opinión no fuera a dañar los intereses de la sociedad en general. De acuerdo con el diario colombiano El Tiempo, el exmandatario peruano Alejandro Toledo recibió 20 millones de dólares de Odebrecht. En Colombia existió una acusación dirigida por el fiscal general contra el expresidente Juan Manuel Santos de haber recibido un millón de dólares para financiar su campaña de 2014 y luego se denunció la vinculación del fiscal Martínez Neira al caso de corrupción. Igualmente en Guatemala, el exministro de comunicaciones Alejandro Sinibaldi, miembro de una reconocida familia, es acusado de recibir sobornos. En los tres países la fiscalización está a cargo de equipos multidisciplinarios donde actúan muchos profesionales de la auditoría.

Como vemos, el profesional de la contaduría se desenvuelve en los campos estatal o gubernamental y privado. En el Estado los informes de auditoría, para los casos de estudio, no revelaron anomalías relacionadas con delitos vinculados a las empresas. En el ámbito privado, las firmas 
que auditaron a las empresas no advirtieron el modelo de negocios aplicado por éstas y el daño social producido por su actuación. El modelo sobre el que se forma al auditor en las universidades carece del suficiente compromiso social, pues se discute la ética desde una perspectiva jurídica e individualista, relacionada con la formación y la actuación individual y no con su vinculación como ciudadano y agente de control social.

En Latinoamérica, el daño ambiental que causan empresas constructoras, mineras y de otras industrias también es considerado un impacto social, desde lo sanitario hasta lo humano. Miles de personas mueren por enfermedades causadas por los compuestos químicos utilizados en las labores extractivas. Los informes de auditoría sólo hacen referencia al impacto ecológico de las operaciones de las industrias en estos países, como un indicador de la gestión ambiental que debe reportarse en procura de aprobación o certificación. El narcotráfico y el tráfico de armas, personas y órganos producen extraordinarias ganancias, dinero que circula en los sistemas financieros de los países, a través de bancos y otras instituciones. La mayoría de los auditores es ajena a esto, no reflexiona sobre estos efectos, pues lo ven como algo que no les compete.

En el sitio web de la constructora Odebrecht, se publica información referida a altos valores éticos. En el informe 2015-2016, se cita su compromiso ético así: "La Organización Odebrecht tiene el compromiso de actuar con ética, integridad y transparencia, en conformidad con las mejores prácticas mundiales de gobernanza y con las leyes aplicables. (El Tiempo, 2015: 26). Seguramente hoy estaremos de acuerdo con que las leyes de diversos países no fueron respetadas, o bien se cumplieron a conveniencia de la compañía. Resulta que la interpretación de la ética empresarial se basa en un modelo de negocios que, aunque daña a la sociedad, es aceptada por las firmas de auditoría.

Lo anterior no significa que la corrupción y el fraude fiscal exista solo desde el momento en que se vincula a altos funcionarios en casos judiciales actuales; ésta ha existido siempre, y a nivel mundial ha sido tratada por muchos autores y desde diferentes perspectivas, entre ellos, filósofos como Thomas Hobbes en su obra "Leviatán". Para el caso de América se originó en la colonización, época durante la cual, quien ocupaba un cargo gubernamental debía pagar una cuota a su jefe inmediato, que en la mayoría de casos era quien lo había nombrado. Esta forma de gobernar incentivó siempre la realización de actos ilícitos por funcionarios públicos. En años recientes, la forma en que se realiza la contratación de empleados de los gobiernos no ha variado mucho en relación con la época colonial; quien financie una campaña política o sea amigo de un funcionario electo, 
seguramente tendrá un puesto gubernamental que deberá pagar de alguna u otra forma, por lo que el salario a devengar será bajo en relación con el costo, lo que lo obliga a buscar otras fuentes de ingresos.

La debilidad de la contaduría pública ha sido enfocarse con exclusividad en los informes financieros, y documentos, sin ver las implicaciones sociales que se desprenden de la información que ellos contienen. El profesional de la contaduría debe sobrepasar la frontera del documento e irse al hecho en sí, esto significa observar alrededor del evento económico a las personas, los resultados y efectos de la inversión. Algunos dirán que esta no es tarea de la auditoría, sin embargo, en el marco de la ética sí lo es, debido a que el dinero que se utiliza mal provoca hambre, muerte, desnutrición, desigualdad, analfabetismo e impide que la sociedad en general mejore el nivel de vida. Londoño, Sánchez y Serna, (2020) aseguran que "el sujeto contable está llamado a configurarse como un elemento de la vida, antes que profesional, ser humano, antes que trabajador, ciudadano; antes que parte del sistema financiero, crítico y con capacidad de incidir en él", lo cual no es más que asumir el compromiso social de una disciplina social.

\section{Reflexión final}

Lejos de pretender concluir debe quedar abierto el debate sobre el ejercicio de la profesión contable y su responsabilidad con la vida de las personas y su entorno ecológico. Los registros contables revelan los eventos económicos de las instituciones, los costos y las ganancias, por lo que su sistema de construcción debe observar con rigurosidad los efectos que las actividades tienen en la vida social y su entorno natural. La construcción de la biocontabilidad, necesariamente nos lleva a la bioauditoría, y el auditor debe salir de lo egocéntrico, alejarse de la perspectiva antropocéntrica para comprender la complejidad del entorno social y natural donde desempeña su labor profesional. La profesión contable no debe alejarse de su responsabilidad de respetar la vida en todas sus formas.

La bioética plantea una transformación de la actitud del profesional contable ante la vida, un paradigma profesional distinto al que hasta el día de hoy ha dirigido el ejercicio profesional a nivel mundial y la formación en las universidades. El auditor debe ser consciente de que es un ciudadano del planeta Tierra, un ser interdependiente y ecodependiente, y en esa perspectiva, la bioética debe ser transversal en la formación universitaria del Contador Público y del Auditor. El diálogo entre lo que se debe hacer y porqué debe hacerse, pensando en lo humano, y en los efectos de las responsabilidades que cada ser tiene como causa de una acción o una omisión, es una directriz de la Bioética, que nos invita a reflexionar sobre el papel de esta profesión en la sociedad, que hoy está en una profunda 
crisis de valores. La redefinición de la profesión contable es pues, un reto desde lo espiritual, lo humano y lo profesional.

\section{Referencias bibliográficas}

1. Beauchamp, T. \& Childress, J. (2009). Principios de Ética biomédica. New York: Oxford University Press.

2. Echenique-Portillo, R. (2009), Mis Apuntes de Bioética. $1^{\text {a }}$ ed. $1^{\text {a }}$ reimp. Ciudad de Méjico: Fondo Editorial FCA.

3. El Tiempo. (2017). Odebrecht colaborará con Fiscalía y reparará a la nación. Recuperado el 14 de Marzo de 2017 de: http://www.eltiempo.com/justicia/cortes/ odebrecht-colaborara-con-fiscalia-por-caso-de-corrupcion-31479.

4. Hobbes, T. (2018) Leviatán. Ciudad de Méjico: Fondo de Cultura Económica

5. IESBA - Consejo de Normas Internacionales de Ética para Contadores. (International Ethics Standards. International Federation of Accountants (IFAC)) (2009) Código de Ética para Profesionales de la Contabilidad. Guatemala.

6. IFAC - Internacional Federation of Accountants. (2011) Normas Internacionales de Auditoría, Pronunciamientos Técnicos. Ciudad de Méjico: Instituto Mexicano de Contadores Públicos y Auditores.

7. Kohler, E. L. (2002). Diccionario para contadores. Ciudad de Méjico: Editorial Limusa, Ed. Reimp.

8. Londoño, M.; Sánchez, L. y Serna, A. (2020). La resignificación del sujeto, como camino a la bioética contable. Bogotá: Universidad de los Andes.

9. Mejía-Soto, E. (2013). Bio-contabilidad: ética, ciencia y tecnología para la sostenibilidad. Libre Empresa, 10 (2), 13-33.

10. Ospina, T. (2018). Más allá de los paraísos fiscales. La ética contable como factor determinante en la construcción de confianza. Teuken Bidikay, 10 (14), 29-42 https:// doi.org/10.33571/teuken.v10n14a1

11. Plata, O.J. (2013). En torno al juicio ético. Consideraciones a partir de Hume y Wittgenstein. Teuken Bidikay, 5 (5), 261-273

12. Sandes, A.N. y Charamelo, A. (2017). Cuando el contexto sobrepasa a la misión y visión: Una mirada sobre las causas de dos escándalos empresariales. Teuken Bidikay, 8 (11), 119-135.

13. Toasa-Guevara, D. E. (2018). Biocontabilidad para la sostenibilidad de la riqueza ambiental. Tesis. Universidad Técnica de Ambato. Ecuador.

14. Potter, van R. (1971). Bioética: Puente hacia el Futuro. New Jersey: Prentice Hall

15. Reich, W. T. (1994). Enciclopedia de Bioética. New York: McMillan.

Para citar este artículo:
Aguilar-Argueta, P. I. (2020). Redefiniendo al auditor desde la bioética. Teuken Bidikay, 11 (17). 79-89. doi:10.33571/teuken.v11n17a4

Ge: RNS. 
Cuando se pueda andar por las aldeas

y los pueblos, sin ángel de la guarda.

Cuando sean más claros los caminos

y brillen más las vidas que las armas.

Cuando los tejedores de sudarios

oigan llorar a Dios entre sus almas.

Cuando en el trigo nazcan amapolas

y nadie diga que la tierra sangra.

Cuando la sombra que dan las banderas

sea una sombra honesta y no una charca.

Cuando la libertad entre a las casas

con el pan diario, con hermosa carta.

Cuando la espada que usa la justicia

aunque desnuda se conserve casta.

Cuando reyes y siervos juntos al fuego,

fuego sean de amor y de esperanza.

Cuando el vino excesivo se derrame

y entre las copas viudas se reparta.

Cuando el pueblo se encuentre y con sus manos

teja él mismo sus sueños y su manta.

Cuando de noche grupos de fusiles

no despierten al hijo con su habla.

Cuando al mirar la madre no se sienta dolor

en la mirada y en el alma.

Cuando en lugar de sangre en el campo

corran caballos y flores sobre el agua.

Cuando la paz recobre su paloma

y acudan los vecinos a mirarla.

Cuando el amor sacuda las cadenas

y le nazcan dos alas en la espalda.

Sólo en aquella hora podrá el hombre

decir que tiene patria.

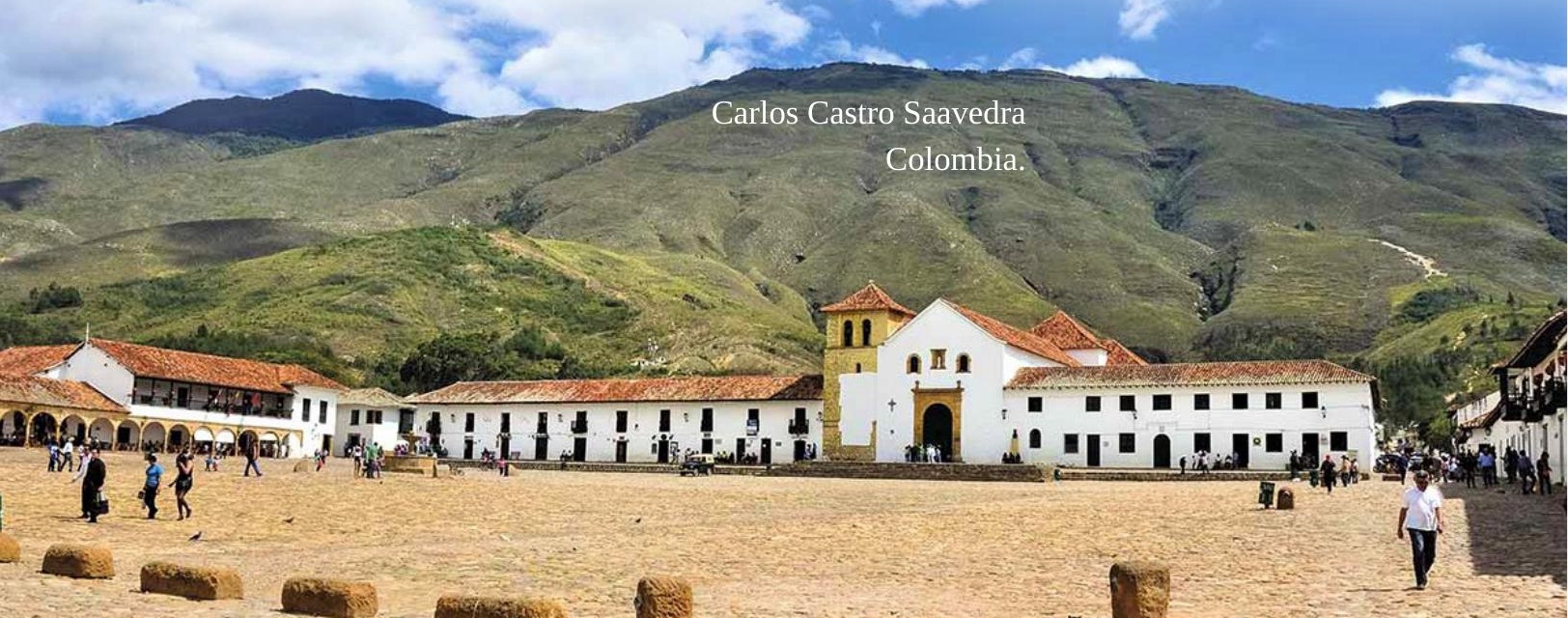

